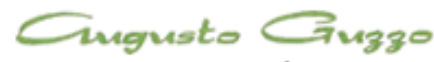

REVISTA ACADEMICA

\title{
Recrutamento e Seleção: \\ O valor do capital intelectual para as organizações
}

\author{
Débora de Jesus Morgado', Jéssica Vivanco Costaํ e Juliana Onder da Silva ${ }^{1}$ \\ Recebido em: 23/04/2013. Aprovado em: 15/05/2013. Disponibilizado em: 26/06/2013
}

1. Débora de Jesus Morgado, Jéssica Vivanco Costa e Juliana Onder da Silva pertencem ao grupo de estudo da Universidade Paulista de São José dos Campos. Instituto de Ciências Sociais e Comunicação. Curso: Administração de Empresas e suas Ênfases, em 2012.

\section{Resumo}

O artigo aponta a relevância do setor de Recrutamento e Seleção (R\&S) e disponibiliza aos profissionais da área as formas de realizar a atividade. Mostra a compatibilidade do cargo com a vaga disponível. Traça o perfil desejável do profissional para a vaga, disponibilizando informações bem definidas e com uma gama de opções, mostra os testes mais adequados para detectar o perfil do entrevistado. Esclarece que é indispensável o entrevistador conhecer bem a vaga, entender a missão da organização e a sua necessidade momentânea e escolher o melhor candidato para a vaga. As organizações atuais procuram aumentar o capital intelectual da desde o momento do recrutamento e seleção. Apresenta métodos eficientes para detectar candidatos que se adéquam às necessidades organizacionais. $\mathrm{O}$ que aumento a eficácia das contratações é a assertividade da escolha das técnicas de seleção para aproximar o perfil da vaga com o perfil do candidato.

Palavras-chave: Recrutamento, Seleção, Vaga, Candidato, Entrevistador.

\begin{abstract}
The article points out the importance of Recruitment and Selection sector (R \& S) and provides professional ways to perform the activity. It shows a job compatibility with the availability. It outlines the desirable profiles of a professional for the job, providing well defined information and with a range of options, showing the most appropriated test to shows the ability an intertwined. It clarifies that it is essential to know the interviewer and the job, understanding the organization mission and its momentary need to choose the best candidate for the job. Nowadays, the organizations seek to increase the intellectual capital since the moment of recruitment and selection. Presenting efficiently methods to detect candidates which fit organizational needs. What increases the effectiveness of hiring is the assertiveness of selection techniques choice to approximate the profile of the vacancy with the candidate's profile.
\end{abstract}

Keywords: Recruitment, Selection, Vacancy, Candidate, Interviewer. 


\section{Introdução}

Este artigo abordará fatores esclarecedores sobre a importância do setor de R\&S. Tratará dos benefícios e malefícios, do processo. Chama atenção para pessoa, no caso, o funcionário que aplicará a Entrevista e a Seleção. Os autores utilizados na investigação apontam que é imprescindível ao processo um profissional responsável e bem preparado.

O valor de uma empresa e seu poder no mercado é avaliado através de fatores como a sua capacidade de desenvolvimento, satisfação do cliente com a qualidade, acessibilidade e disponibilidade de seus produtos e serviços. A alta eficácia no tripé das funções de marketing, finanças e produção, entre vários outros, destaca o seu mais valioso bem e a sua maior força, o conhecimento e as informações. A união de ambos dentro de uma empresa é o chamado capital intelectual, imprescindível para o sucesso da organização. A sua captura depende de um setor de Recrutamento e Seleção - R\&S competente. O R\&S busca no mercado de Recursos Humanos o maior contingente humano qualificado para suprir as necessidades da vaga e o submete à seleção.

Enquanto o recrutamento mobiliza a maior quantidade de candidatos a seleção trata de escolher entre eles, os mais adaptáveis ao perfil das vagas.

O Recrutamento segundo Jaqueline Arruda (2009) é “[...] um conjunto de técnicas e procedimentos que visa atrair candidatos potencialmente qualificados e capazes de ocupar cargos dentro da organização." Seleção (GOMES ET AL., 2003, P. 3) é o “[...] processo pelo qual os candidatos a um cargo são separados e entrevistados. É tomada de decisão de contratar".
O Recrutamento e Seleção faz parte de um processo que abrange a empresa como um todo, desde a contratação até a demissão de um funcionário. É responsável pelo processo seletivo, buscando o melhor capital intelectual e o mais adequado para a vaga disponível, já que atualmente as pessoas de uma corporação são os maiores responsáveis pela capitação dos recursos organizacionais. Um profissional que aplica esse processo deve ser experiente e conhecer as necessidades da vaga para obter eficácia.

\section{Perfil e Histórico}

As mudanças são constantes no universo. Cada dia que passa as organizações sofrem transformações, e ultimamente as mudanças causam um impacto nunca ocorrido antes. Estudos mostram que todas as áreas como a tecnologia os fatores sociais, culturais, ecológicos, legais, econômicos e demográficos sofrem alterações, mas a área de Recursos Humanos - RH é que mais se modifica.

O Setor de Recursos Humanos surgiu no século XIX, com a intenção de facilitar o controle dos funcionários. Os chamados "Chefes" eram temidos, por sua falta de tato com as pessoas, não tinham flexibilidade alguma e eram extremamente rígidos. Um funcionário que era chamado por ele já se dirigia ao setor com o pensamento de que seria demitido. As empresas de grande porte foram as responsáveis por começar a mudança, que deu início aos investimentos na área da sociologia e psicologia. Estas ciências tentaram fazer com que as pessoas deixassem de serem vistas como máquinas e objetos e passassem a ser vistas como seres humanos.

"O panorama industrial do início do século tinha todas as características e elementos para poder inspirar uma 'Ciência da Administração': uma 
variedade incrível de empresas, com tamanhos altamente diferenciados, problemas de baixo rendimento da maquinaria utilizada, desperdício, insatisfação generalizada entre os operários, concorrência intensa, mas com tendências pouco definidas, elevado volume de perdas envolvido quando as decisões eram mal formuladas." (CHIAVENATO, 1993, p.54).

Frederick W. Taylor em meados de 1903 - 1906 escreveu sobre a maximização da eficiência na produção. Em 1916 Henri Fayol desenvolveu as funções do administrador: planejar, organizar, coordenar, comandar e controlar. Em 1920 começou-se a verificar a relação empregado e empregador, tentando eliminar conflitos e passando a buscar um ambiente mais harmônico, reduzindo os custos e aumentando os ganhos. Em 1945 surgiram questões legais e sindicais, o que fez com que a satisfação e motivação dos colaboradores se tornassem ainda mais importantes. Cinco anos depois em 1950 o chamado Gerente de Pessoal tornou-se Gerente de Recursos Humanos. Em 1960 veio o Gerente de relações industriais para distinguir quem cuidaria de questões administrativas e quem cuidaria do aspecto Humano.

No decorrer dos anos a teoria exposta por Chiavenato passou por algumas mudanças. Atualmente a satisfação do funcionário é um fator crucial para o sucesso da empresa. Além de manter esse equilíbrio, entre o bem estar dos funcionários e o sucesso organizacional, surge outro desafio para os Recursos Humanos, a busca e a manutenção de novos talentos. Por todos esses motivos esse departamento que é de nível tático operacional é um dos mais importantes da organização. Dentre as responsabilidades do Setor de Recursos Humanos se destaca o processo de
Recrutamento e Seleção atendendo à necessidade de preenchimento das vagas. Essa área nos dias de hoje, faz todas as contratações e demissão da organização.

A visão de futuro empresarial deve englobar em sua perspectiva os recursos humanos, e isso pode ser percebido nas palavras de Robbins (2008) quando afirma: "As necessidades futuras de recursos humanos são determinadas pelos objetivos e estratégias da organização. A demanda de RH é resultado da demanda pelos produtos ou serviços e níveis de produtividade da organização. Com base em sua estimativa de receita total, a administração pode estabelecer o número e a combinação de recursos humanos necessários para alcançar essa receita”.

\section{Descrição Conceitual}

\subsection{Administração de Recursos Humanos (ARH)}

Segundo Robbins (2001): “A administração de Recursos Humanos é a parte da organização que trata da dimensão de "pessoas", [...] pode ser considerada por um dos dois modos: primeiro, a administração de RH é uma função do staff de RH ou de apoio na organização. Seu papel é prestar ajuda em questões de administração de $\mathrm{RH}$ aos empregados de linha, ou seja, aqueles diretamente envolvidos na produção de bens e serviços da organização. Segundo, a administração é uma função de todos os administradores".

De acordo com Robbins (2001) a administração de Recursos Humanos é constituída por quatro funções básicas:

a) Preenchimento de cargos,

b) Treinamento e Desenvolvimento,

c) Motivação 
d) Manutenção.

Que em outras palavras definidas em termos menos acadêmicos podem ser denominados:
a) Recrutar Empregados
b) Prepará-los
c) Estimulá-los
d) Mantê-los na Organização.

Robbins (2001) diz que é indispensável que um executivo, atuante ou não, de um departamento formal de Recursos Humanos exerça as quatro funções básicas para a saúde da organização através do olhar sobre os funcionários.

Afinal de contas segundo Mayo (2003) "[...] quanto melhor o tratamento dado às pessoas, maior a chance de a organização ser bem sucedida". The Times (2010) afirma que os dados que realmente diferenciam as empresas atraentes das comuns são os referentes aos investimentos em Pesquisa, Desenvolvimento, investimentos no desenvolvimento humano, índices de fidelidade do consumidor e porcentagem de atrito no quadro de profissionais. Esse dado investimento em desenvolvimento humano é o responsável pela geração dos demais fatores.

É por isso que Mayo (2003) aborda em suas conclusões que o quadro de funcionários é o maior ativo de uma empresa, pois valores muito mais altos estão sendo dados recentemente a "ativos intangíveis" que são os conhecimentos, a competência, a marca e os sistemas. Ativos estes que também são conhecidos como capital intelectual.
Segundo Welch (1999 apud MAYO 2003, p. 2), “existem três medições fundamentais nos negócios - satisfação do cliente, satisfação do funcionário e fluxo de caixa, nesta ordem”. Recentemente Jack Welch declarou estar enganado quanto à ordem dos dois primeiros já que o primeiro lugar deveria pertencer aos funcionários, pois de acordo com Mayo (2003) "[...] Welch percebeu que tudo dependia das pessoas: a aptidão, a motivação, a criatividade, as habilidades organizacionais e a liderança. As pessoas além de administrarem os ativos tangiveis, também mantém e desenvolvem os intangiveis".

Através de toda essa reflexão sobre o valor do capital intelectual ressaltando o ponto de quanto às pessoas agregam conhecimentos, experiência e ideias e de como são essenciais para a organização percebe-se a importância da Administração de Recursos humanos - ARH e de sua função de preenchimento de cargos, abordando principalmente o setor de "Recrutamento e Seleção".

\subsection{Recrutamento de Pessoal}

Segundo Robbins (2001): “A administração de Recursos Humanos é a parte da organização que trata da dimensão de "pessoas", [...] pode ser considerada por um dos dois modos: primeiro, a administração de RH é uma função do staff de $\mathrm{RH}$ ou de apoio na organização. Seu papel é prestar ajuda em questões de administração de RH aos empregados de linha, ou seja, aqueles diretamente envolvidos na produção de bens e serviços da organização. Segundo, a administração é uma função de todos os administradores". 
Figura 1.1. Administração de RH

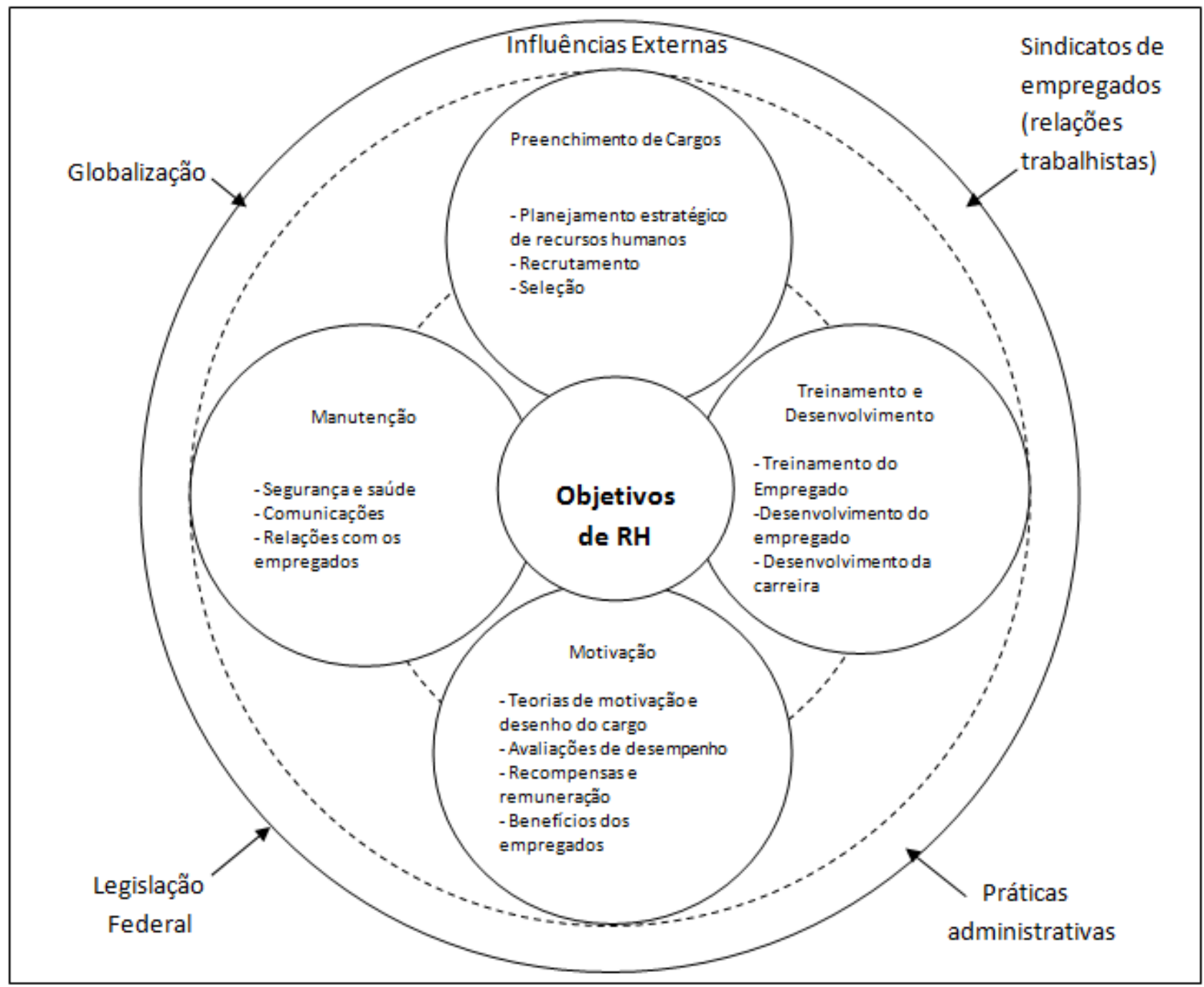

Fonte: Robbins (2001).

"Recrutamento é um conjunto de técnicas que atrai candidatos qualificados e capazes de ocupar cargos dentro da empresa. É basicamente um sistema de informação onde a empresa divulga as vagas que estão disponíveis. [...] Da mesma forma como os indivíduos atraem e selecionam as organizações, se informando e formando opiniões a respeito delas, as organizações procuram atrair indivíduos e obter informações a respeito deles para decidir sobre o interesse de admiti-los ou não." (CHIAVENATO, 1999, p.25).

De acordo com Sorio (2007) '"...] As organizações precisam de pessoas que, além de conhecimento técnico, tenham como competências essenciais a curiosidade pelo aprendizado, a flexibilidade, a capacidade de adaptação às mudanças, a facilidade no trato interpessoal e o sentido de urgência que o mundo atual nos imprime".

Complementando o assunto abordado Sobral e Peci (2012) dizem que "O 
recrutamento é o processo de localização, identificação e atração de candidatos qualificados para ocupar um cargo na estrutura de pessoal da organização".

Recrutamento de pessoal é a primeira etapa do processo de seleção, é a fase em que o responsável de ARH avalia o cargo disponível e traça o perfil do profissional que virá a ocupá-la, buscando no mesmo além dos requisitos exigidos pelo cargo as competências essenciais. O recrutamento dentro de uma organização se inicia quando se decidi aumentar ou substituir seu quadro de funcionários. A primeira fase de um recrutamento é a seleção de currículos onde tem informações pessoais do candidato, habilidades profissionais, conhecimentos e experiências anteriores.

Lodi (1967) define recrutamento como um processo de procurar empregados. Onde os candidatos estão em busca de experiência profissional, novos conhecimentos, salário, e os empregadores interessados em profissionais qualificados para atender as necessidades exigidas.

Quais as vagas oferecidas pelo mercado de trabalho, quantos e quais são os candidatos disponíveis? São três perguntas chaves para a decisão de qual o tipo de recrutamento utilizar, e onde procurar estes candidatos. Recrutamento faz parte de todas as empresas, seja ela de pequeno, médio ou grande porte, cada uma delas busca uma forma de recrutamento mais adequada ao perfil da vaga e do candidato mais adequado à cultura da organização.

Existem duas formas de recrutamento dentro das organizações, recrutamento interno e recrutamento externo.

\subsubsection{Recrutamento Interno}

Segundo Gil (2001), o processo de Recrutamento interno tem o objetivo de motivar os funcionários, oportunizar o desenvolvimento de uma carreira profissional e agregar qualidade nos produtos e serviços da empresa. Estes são os aspectos positivos envolvidos no processo, porém é fundamental estar atento às características da empresa, sua cultura e políticas. Uma empresa que necessita de mão de obra especializada, e desenvolve profissionais para determinadas funções, pode enfrentar problemas se fizer com frequência, movimentações internas. Em outras palavras o recrutamento interno é quando a própria empresa movimenta ou desloca internamente os seus funcionários de cargo. Assim ela não precisa recorrer ao recrutamento no mercado de $\mathrm{RH}$ externo.

Segundo Ribeiro (2005), "se um empregado sabe que pode avançar dentro da empresa, sente-se encorajado para buscar o autodesenvolvimento".

$$
\text { Para Sobral e Perci (2012) “O }
$$
recrutamento interno consiste no preenchimento de uma vaga, para um posto de trabalho, mediante a realocação de funcionários atuais, que podem ser promovidos ou transferidos de outras unidades".

De acordo com Tachizawa, Ferreira e Fortuna (2001) "no recrutamento interno, o empregado é recrutado dentro da organização". Esse processo costuma envolver:

- Movimentação Horizontal

a) Transferências

b) Promoções

- Ascensão Funcional

a) Promoções com transferências

b) Programas de desenvolvimento de pessoal 
c) Plano de Carreira

O recrutamento interno evita grandes despesas como: despesas com divulgação, agência de emprego e custos com período de integração.

O candidato é observado pelo seu superior, sendo assim a margem de acerto é maior.

E segundo Ribeiro (2005), este recrutamento só deve ser feito desde que um candidato da casa tenha condições de, no mínimo, igualar-se ao antigo ocupante, dentro de determinado prazo.

\subsubsection{Vantagens do Recrutamento Interno}

Segundo Araújo e Garcia (2009) as vantagens do recrutamento interno são:

- Necessidades de investimentos de menor ordem;

- Rapidez no processo;

- Disponibilidade de investimentos para outras atividades;

- Segurança em relação aos seus recursos humanos;

- Motivação das pessoas.

\subsubsection{Desvantagens do Recrutamento Interno}

Algumas desvantagens de um recrutamento interno Segundo Chiavenato (1999):

- Pode bloquear a entrada de novas ideias, experiências e expectativas;

- Facilita o conservantismo e favorece a rotina atual;
- Mantém quase inalterado o atual patrimônio humano da organização;

- Ideal para empresas burocráticas e mecanísticas;

- Mantém e conserva a cultura organizacional existente;

- Funciona como um sistema fechado de reciclagem contínua.

Os funcionários escolhidos podem ser frustrados, prejudicando sua produtividade no trabalho. Pode gerar um conflito de interesses, pois as oportunidades de crescimento dentro da organização tende a criar uma atitude negativa nos empregados que por não demonstrarem condições, não acessam aquelas oportunidades. "Quando não é bem estruturada, a promoção interna pode transformar-se numa espécie de carreirismo, deixando de lado a eficiência funcional no exercício das funções atuais" (NUNES, 2002, p.31).

\subsubsection{Recrutamento Externo}

Recrutamento externo é a busca de candidatos fora da empresa. Ele acontece quando não tem funcionários com o perfil desejado dentro da organização para preencher a vaga disponível.

Para Sobral e Perci (2012) “O recrutamento externo, ocorre quando a organização abre o processo de recrutamento a candidatos externos a organização”.

Segundo Ribeiro (2005), as principais fontes de recrutamento externo são:

- Anúncio de jornal

- Cartazes e panfletos

- Apresentação de funcionários 
- Agencias de empregos

- Anúncios em emissoras de rádio

- Serviço de alto-falantes

- Estagiários

- Contatos com outras empresas

- Guardas-mirins

- Escolas técnicas

- Mão de obra temporária

- Internet.

- Cadastro de currículos

Sobral e Peci (2012) apud Martinez (2001, p. 48-51) afirmam que "Algumas fontes de recrutamento apresentam melhores resultados que outras. Em geral, as indicações ou recomendações por parte de trabalhadores atuais produzem melhores candidatos". "Isso acontece porque a pessoa que recomenda conhece os requisitos exigidos pelo cargo e as qualificações e habilidades do candidato. Por outro lado, o funcionário atual apenas recomendará outra pessoa se sentir que isso não afetará negativamente sua reputação e seu prestígio na organização. No entanto, apesar de ser um método de recrutamento mais confiável, não deve ser o único utilizado, pois pode resultar em uma força de trabalho muito homogênea e pouco diversa (por exemplo, funcionários todos formados na mesma universidade)". (SOBRAL E PECI, 2012).

Chiavenato (2002) diz que "O Currículum Vitae (CV) assume enorme importância no recrutamento externo. Funciona como um catálogo, currículo ou portfólio do candidato. O CV é apresentado em varias seções: dados pessoais (informações básicas, como, nome, idade, endereço, e telefone para contatos), objetivos pretendidos (cargo ou posição desejada), formação escolar (cursos feitos), experiência profissional (empresas onde trabalha e trabalhou) e habilidades e qualificações profissionais (principais pontos fortes e competências pessoais)".

\subsubsection{Vantagens do Recrutamento Externo}

Assim como o recrutamento interno o externo também possui vantagens e desvantagens, e as vantagens do recrutamento externo, segundo Chiavenato (2008) são abordadas como:

- Traz sangue novo na organização: talentos, habilidades e expectativas;

- Enriquece o patrimônio humano pelo aporte de novos talentos e habilidades;

- Aumenta o capital intelectual ao incluir novos conhecimentos e destrezas;

- Renova a cultura organizacional e a enriquecem com novas aspirações;

- Incentiva a interação da organização com o mercado de recursos humanos;

- Indicado para enriquecer mais intensa e rapidamente o capital intelectual.

\subsubsection{Desvantagens do Recrutamento Externo}

Segundo Robbins (2001) as Desvantagens não são consideradas muitas, porém existem, e são fatores nos quais se deve ter total atenção. Afinal de contas o candidato é algo novo para a organização que não conhece a pessoa, pois mesmo sendo muitas vezes indicação de alguém continua sendo alguém que não tem conhecimento dos métodos e cultura da empresa na prática. Essas desvantagens são: 
- Mais demorado que o recrutamento interno, pois o processo seletivo exige um tempo maior;

- Mais caro;

- É mais perigoso que o recrutamento interno, pois não se conhece o candidato.

\subsubsection{Recrutamento Mix}

Por último, porém não menos importante, temos a opção de recrutar e selecionar de forma mista em que, como o próprio rótulo sugere, a organização usufruirá algumas vantagens em realizar internamente tais atividades e outras oriundas da forma externa. Pode-se arriscar a dizer que as organizações em geral não utilizam somente o recrutamento interno ou externo. Eles não são excludentes, pelo contrário, se completam (ZOU-AIN, 2003).

Segundo Chiavenato (2009) Na prática, as empresas nunca praticam apenas recrutamento interno ou externo. Eles se complementam e se completam. Ao fazer um recrutamento interno, $\mathrm{o}$ individuo deslocado para a posição vaga precisa ser substituído em sua posição atual. E se é substituído por outro funcionário, o deslocamento produz uma vaga que precisa ser preenchida. Quando se faz o recrutamento interno em algum ponto da organização surge sempre uma posição a ser preenchida pelo recrutamento externo, a menos que esta seja cancelada. Por outro lado sempre que se faz recrutamento externo, algum desafio, oportunidade ou horizonte deve ser oferecido ao novo funcionário sob pena deste procurar desafios e oportunidades em outra organização que lhe pareça melhor.

Se a empresa utilizar o recrutamento interno e o externo simultaneamente ela está lançando mão de outro processo, o recrutamento misto.

Segundo Chiavenato (2009) O recrutamento misto pode ser adotado em três alternativas de sistema:

a) Inicialmente, recrutamento externo, seguido de recrutamento interno, caso aquele não apresente resultados desejáveis. A empresa está mais interessada na entrada de recursos humanos do que em sua transformação, ou seja, a empresa necessita de pessoal já qualificado no curto prazo e precisa importá-lo do ambiente externo. Não encontrando candidatos externos à altura, lança mão do seu próprio pessoal não considerando de início os critérios acerca das qualificações necessárias.

b) Inicialmente, recrutamento interno, seguido de recrutamento externo, caso não apresente resultados desejáveis. A empresa dá prioridade a seus empregados na disputa das oportunidades existentes. Não havendo candidatos internos à altura, parte para $\mathrm{O}$ recrutamento externo.

c) Recrutamento externo e recrutamento interno, concomitantemente: é o caso em que a empresa está mais preocupada com o preenchimento de vaga existente, seja por meio de input ou mediante transformação de recursos humanos. Uma boa política de pessoal dá preferência aos candidatos internos sobre os externos, em casos de igualdade de condições entre eles. Com isso, a empresa se assegura de que não está descapitalizando os recursos humanos, ao mesmo tempo em que cria condições de sadia competição profissional.

$\mathrm{Na}$ organização o recrutamento é o processo de captação e a seleção é o processo de exclusão. 


\subsection{Seleção}

\subsubsection{Seleção de Pessoas}

Segundo Chiavenato (2009) "A seleção de pessoas busca entre os candidatos recrutados aqueles mais adequados aos cargos existentes na empresa, visando manter ou aumentar a eficiência e o desempenho do pessoal, bem como a eficácia da organização".

Nas palavras de Sobral e Peci (2012) "[...] No processo de seleção, avaliam-se as competências e qualificações dos candidatos e sua adequação as exigências do cargo".

Após a identificação de um determinado grupo de candidatos, o próximo passo é a Seleção, neste processo são avaliadas as competências e qualificações dos candidatos e sua adequação as exigências do cargo.

Na prática, a Seleção de Pessoas é uma previsão de qual candidato irá ter o melhor desempenho no cargo, como se trata de pessoas, não são analisadas apenas as habilidades, mas também a personalidade e o percurso da vida do candidato.

Para auxiliar os administradores neste processo, existem instrumentos e técnicas que são utilizados para avaliação dos candidatos.

\subsection{Instrumentos e Técnicas de Seleção}

As técnicas utilizadas na seleção de pessoas podem ser classificadas em cinco grupos: entrevista, seleção, prova de conhecimento ou capacidade, testes psicológicos, testes de personalidade e técnicas de simulação (CHIAVENATO, 2009).
Elas são necessárias para estabelecer um parâmetro para o administrador, a mais conhecida e utilizada pelas empresas é a Entrevista de Seleção. Algumas empresas utilizam duas ou mais técnicas na avaliação.

\subsubsection{Entrevistas de Seleção}

Para os autores França e Arellano (2002) a entrevista é o instrumento mais importante no processo de seleção de pessoal e deve ser realizada por questões semi estruturadas.

As entrevistas possibilitam que $\mathrm{O}$ avaliador tenha contato direto com o candidato, através deste contato o avaliador busca conhecer melhor o candidato.

De acordo com Robbins (2008) antes de se reunir com o candidato, você deve se preparar, examinando sua ficha de inscrição, currículo, além da descrição e especificação do cargo para a vaga que ele está sendo entrevistado.

Segundo Chiavenato (2009) a entrevista de seleção merece cuidados especiais que podem promover seu aperfeiçoamento. Seu desenrolar passa por cinco etapas, que são elas:

- Preparação da entrevista: ela deve ser preparada antecipadamente, é necessário selecionar perguntas que agregam informações podendo ser utilizadas na comparação entre o que o cargo exige e o que o candidato oferece.

- Ambiente: deve ser preparado com o objetivo de evitar ruídos e interferências externas. Considerar também o ambiente psicológico que deve ser ameno e cordial.

- Processamento da entrevista: deve levar em consideração dois aspectos, o material e o formal, que são intimamente relacionados. $O$ material constitui $O$ conteúdo da entrevista, isto é, o conjunto de 
informações que o candidato fornece a seu respeito, e o formal é o comportamento do candidato, é a maneira como o candidato se comporta e reage dentro da situação. $\mathrm{O}$ entrevistador deve considerar ambos os aspectos para uma adequada avaliação dos resultados.

- Encerramento da entrevista: o entrevistador deve fazer algum sinal claro para demonstrar o fim da entrevista, sobretudo proporcionar ao entrevistado algum tipo de informação quanto à ação futura, como será contatado para saber o resultado.

- Avaliação da entrevista: logo que o entrevistado deixa a sala, o entrevistador terá que concluir a tarefa de avaliar o candidato, deve registrar os aspectos mais importantes, e após o término de todas as entrevistas fazer uma avaliação definitiva e a tomada de decisão.

\subsubsection{Provas de Conhecimento ou de Capacidade}

Os testes de conhecimento ou de capacidade podem medir o grau de conhecimento e habilidades do candidato, e, devem ser tomados alguns cuidados na elaboração do teste como: colocar frases curtas, não deve ter duplo sentido e evitar numero grande de títulos (PONTES 2004).

Os testes de conhecimento medem as habilidades intelectuais dos candidatos, como por exemplo, a capacidade de raciocínio rápido, de resolução de problemas, da aprendizagem rápida a parti de uma experiência concreta e de processamento de informação.

Segundo Chiavenato (2009), há uma variedade de provas de conhecimentos ou de capacidade, razão pela qual costumamos classificá-las quanto a: maneira, área abordada e forma.

- Classificação quanto à maneira como as provas são aplicadas

Provas orais: são provas aplicadas verbalmente por meio de perguntas $\mathrm{e}$ respostas orais.

Provas escritas: são provas aplicadas por escrito por meio de perguntas e respostas escritas.

Provas de realização: são provas aplicadas por meio de execução de um trabalho ou tarefa.

- Classificação quanto à área de conhecimentos abrangidos

Provas gerais: servem para aferir noções de cultura geral ou generalidade de conhecimento.

Provas específicas: servem para pesquisar conhecimentos técnicos e específicos diretamente relacionados à posição em referência.

- Classificação quanto à forma como as provas são elaboradas

Provas tradicionais: são provas do tipo dissertativo e expositivo, podem ser improvisadas, pois não exigem planejamento.

Provas objetivas: são provas estruturadas na forma de testes objetivos, cuja aplicação e correção são rápidas e fáceis.

Provas mistas: são provas que utilizam tanto perguntas dissertativas quanto itens em forma de testes.

\subsubsection{Testes Psicológicos}

Os testes psicológicos são instrumentos padronizados que serve de estímulo a um 
comportamento por parte do entrevistado, França (2007).

\section{Segundo Pontes (2004), os testes psicológicos buscam por avaliar características individuais do candidato em relação aos requisitos do cargo.}

De acordo com Fiorelli (2007) "Os resultados de testes e entrevistas psicológicas constituem material para apoiar a escolha pelos administradores e gestores. Os mesmos têm utilidade nas situações de impasse, quando vários candidatos apresentam experiência técnica similar, quando as entrevistas não levam a resultados conclusivos e os responsáveis pela decisão procuram dados neutros em que possam apoiar-se".

\subsubsection{Testes de Personalidade}

Segundo Chiavenato (2009), os testes de personalidade servem para analisar os diversos traços de personalidade, sejam eles determinados pelo caráter (traços adquiridos ou fenotípicos) ou pelo temperamento (traços inatos ou genotípicos). Um traço da personalidade é uma característica marcante da pessoa, capaz de distingui-la das demais.

Segundo Chiavenato (2009), tanto a aplicação como interpretação dos testes de personalidade exigem necessariamente a participação de um psicólogo. Porém muitas empresas não possuem este profissional e esta atividade é praticada por profissionais estagiários, administradores ou pedagogos.

\subsubsection{Técnicas de Simulação}

Conforme Pontes (1996), as técnicas de dinâmicas de grupo ou simulação são atividades estruturadas que podem ser utilizadas para treinar ou selecionar pessoas. Em seleção, as técnicas são aplicadas para observar diversas características comportamentais. É como um jogo: a partir de uma atividade proposta são estabelecidos objetivos e regras, cabendo a cada participante utilizar suas habilidades pessoais para chegar ao objetivo, neste caso a oportunidade de emprego.

As técnicas de simulação procuram passar do tratamento individual e isolado para o tratamento em grupos, e do método exclusivamente verbal ou de execução para a ação social (CHIAVENATO, 2009).

O teste de personalidade é fundamental para analisar como o candidato se relaciona com outra pessoa, analisar também como é a sua autoconfiança, sua autonomia, introversão, capacidade de decisão e de controle emocional.

\subsection{A Eficiência e a Eficácia do Processo Seletivo}

O processo seletivo precisa ser eficiente e eficaz. A eficiência do processo seletivo consiste em fazer corretamente as coisas que são segundo Chiavenato (2009) “[...] Saber entrevistar bem, aplicar testes de conhecimentos que sejam válidos e precisos, dotar a seleção de rapidez e agilidade, contar com um mínimo de custos operacionais, envolver as gerências e suas equipes no processo de escolher candidatos entre outros". A eficácia consiste em alcançar resultados e atingir objetivos: saber trazer os melhores talentos para a empresa e, sobretudo, tornar a empresa cada dia melhor com as novas aquisições de pessoal.

Para saber se o Processo Seletivo foi eficiente e eficaz deve fazer uma avaliação e controle dos resultados.

Segundo Chiavenato (2009) Para medir a eficiência do processo, deve-se levar em conta uma estrutura de custos que permita uma análise adequada, a saber: 
a) Custos de Pessoal: que incluem o pessoal que administra os processos de provisão de pessoas, seus salários e encargos sociais, bem como o tempo do pessoal de linha (gerentes e suas equipes) aplicado nas entrevistas com candidatos.

b) Custos de operação: que incluem telefonemas, telegramas, correspondências, honorários de profissionais e de serviços envolvidos (agências de recrutamento, consultorias, etc.) anúncios em jornais e revistas, despesas de viagens de recrutamento, despesas com exames médicos de admissão, serviços de informação cadastral de candidatos, etc.

c) Custos adicionais: que incluem outros custos, como equipamentos, software, mobiliário, instalações, etc.

Muito do que vimos na parte relacionada com os custos de rotatividade de pessoal pode ser aplicado à avaliação e controle dos resultados de seleção.

Para medir a eficácia do processo de provisão é muito útil a utilização do quociente de seleção, que pode ser calculado por meio da seguinte equação:

$$
\text { Q.S. }=\frac{\text { Número de candidatos admitidos }}{N \text { úmero de candidatos examinados }} \times 100
$$

O quociente de seleção (selection ratio) é o resultado da proporção entre números de pessoas admitidas e o número de candidatos submetidos às técnicas de seleção. À medida que o quociente de seleção diminui, aumenta sua eficiência e seletividade. Em geral, o quociente de seleção sofre alterações provocadas pela situação de oferta e procura no mercado de recursos humanos, como vimos antes.

Existem outras várias medições de rendimento do processo seletivo.

Mas o importante é que haja melhoria continua neste processo, ele não deve ser rígido, condicionado apenas por normas e diretrizes, ele deve ser um processo flexível e ágil para atender a demanda da empresa no momento certo.

Determinadas áreas não podem ter um intervalo de tempo grande entre a demissão de um funcionário e a contratação de outro, ou até mesmo um procedimento moroso na contratação de um funcionário para atender a demanda do mercado.

Através da figura 1.2 - O processo de seleção percebe-se que segundo Robbins (2001) "Para que o processo de recrutamento funcione com eficácia, deve haver um pool significativo de candidatos entre os quais poderão ser escolhidos... e quanto maior a diversidade desse grupo melhor. [...] Quanto mais candidatos houver maior a chance do recrutador de encontrar uma pessoa que seja, mas bem qualificada para os requisitos do cargo. Ao mesmo tempo, no entanto, o recrutador deve oferecer informações suficientes sobre $\mathrm{O}$ cargo para que candidatos não qualificados desistam de se apresentar." Afinal de contas colocar os candidatos não qualificados no processo só aumentará o custo e o tempo de seleção. 
Figura 1.2 - O processo de Seleção

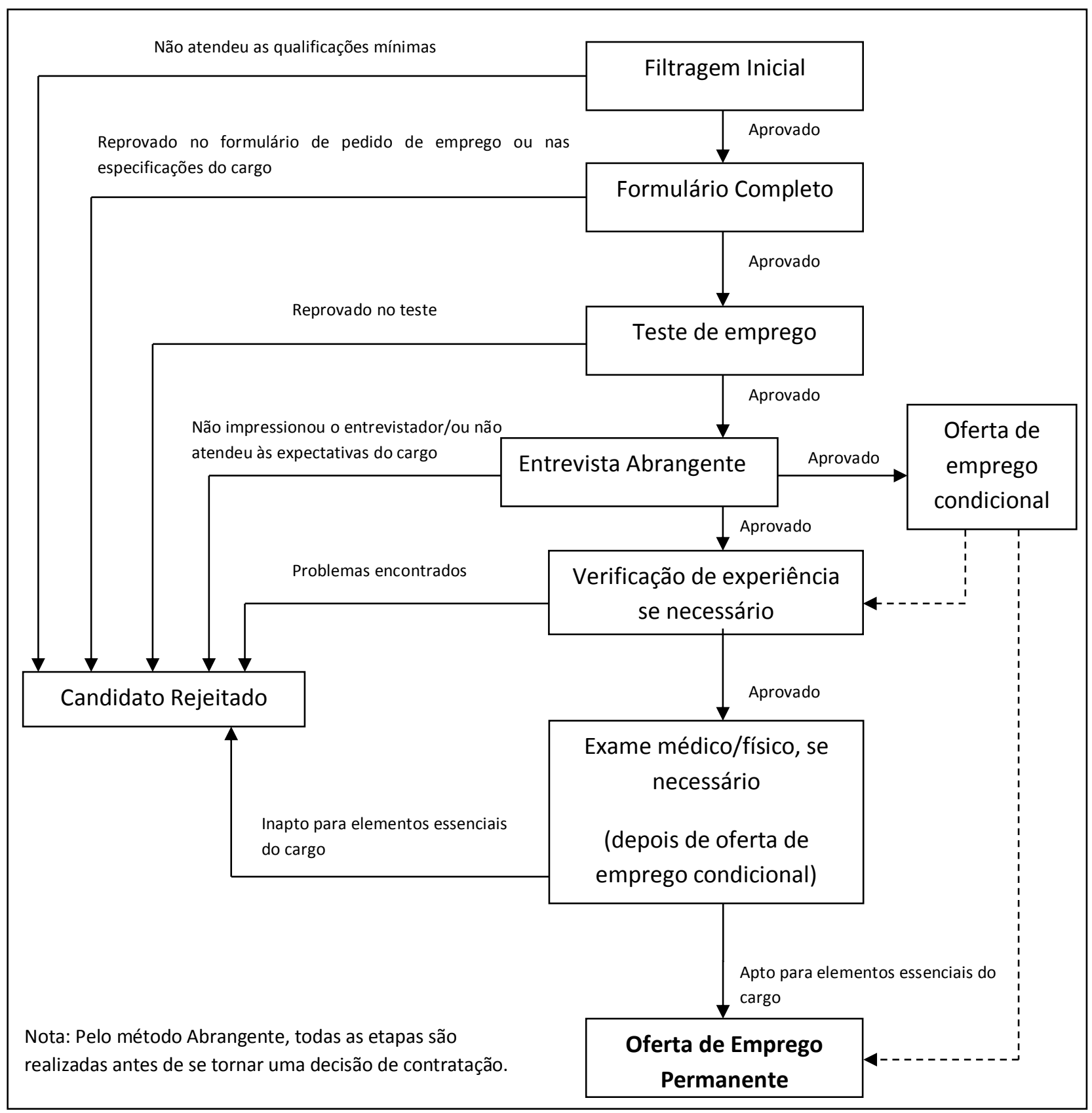

Fonte: Robbins (2003).

\section{Plano de Melhoria}

Com base na teoria abordada e na análise do estudo prático que foi realizado em uma organização que atua no sistema financeiro brasileiro, onde a sua maior força de trabalho são os funcionários e que utiliza um único tipo de recrutamento, o que gera alguns problemas.

Nesta organização foram realizadas visitas em alguns pontos de atendimento da organização, e a parti deste estudo identificamos e entendemos as falhas do 
processo seletivo, constatamos grande desperdício de capital intelectual, provocando não apenas prejuízos financeiros, mas também impacto relevante em outras áreas da organização, interferindo principalmente no valor da empresa para o cliente final.

Atualmente o processo de seleção desta organização é realizado através do recrutamento externo e o instrumento de seleção utilizado é a prova de conhecimento, mas diferentemente da maioria dos concursos promovidos no Brasil, esta organização não faz avaliação especifica para cargos definidos, ela desenvolve apenas uma prova para o cargo inicial, onde a competição pela vaga de emprego é a mesma para quem possui um curso superior e para quem possui apenas o ensino médio.

Analisando a situação, percebemos que este tipo de processo seletivo não favorece nenhum candidato, pois os candidatos que possuem apenas o ensino médio têm dificuldades na prova, pois está competindo à vaga com candidatos com ensino superior, que na teoria tem mais conhecimento $\mathrm{e}$ maior possibilidade de garantir a vaga, porém uma pessoa com graduação e que já atua na área de formação dificilmente participará de um concurso onde ela não poderá exercer sua profissão, tendo que trabalhar inicialmente no cargo de escriturário com salário relativamente abaixo da média do mercado para profissionais com nível superior.

Analisando a organização identificamos que ela tem dificuldades de encontrar funcionários para cargos que exigem qualificação e especialização, e quando encontram tem problemas em ajustar o salário. Para uma organização dinâmica e que está inserida num ambiente altamente competitivo o déficit de profissionais qualificados podem gerar grande perdas financeiras e uma associação negativa à sua marca.

Nas visitas realizadas na organização concluímos que para os funcionários a forma como é realizado o processo seletivo na organização é boa e satisfatória, pois funcionando desta forma as oportunidades de crescimento profissional são grandes na empresa, já que não existe a competitividade externa pelo cargo desejado.

Enfim, apenas os funcionários atuais se beneficiam com a atual forma de recrutamento da organização, uma reestruturação do processo de recrutamento e seleção iria gerar aos candidatos mais motivação para disputar uma vaga de emprego e à empresa um melhor aproveitamento do seu capital intelectual, aumentando a eficácia da sua atividade, desta forma consequentemente os clientes ficariam mais satisfeitos e fidelizados.

Os Recursos Humanos são tão importantes quanto o Planejamento e à Estratégia da organização, pois se os funcionários não estiverem em sintonia com a empresa, a estratégia não irá se concretizar, impedindo a organização de atingir os seus objetivos, por isso se reforça a importância de sanar problemas nesta área e eliminar desperdícios do capital intelectual.

A sugestão de melhoria para esta organização seria manter a prioridade das oportunidades para os funcionários já admitidos e promover mudanças no concurso, estendendo o concurso para cargos pré-definidos com distinção de quem tem curso superior e de quem tem o ensino médio. As avaliações, critérios de aprovação, salários, benefícios e outras condições serão de acordo com o cargo escolhido pelo candidato.

Para mostrar a viabilização da sugestão apresentada fizemos um plano de melhoria. 
O primeiro passo é readequar a forma como é realizado o concurso, além disso, é imprescindível que a política de Recursos Humanos seja reestruturada paralelamente para que os atuais funcionários não sintam nenhuma inconveniência com esta mudança.

Esta readequação é necessária, pois assim diminuirá significativamente todas as dificuldades da organização em encontrar funcionários para cargos que exigem qualificação e especialização e minimizará o desperdício do capital intelectual. Os atuais funcionários continuarão tendo prioridade nas oportunidades dentro da organização e os candidatos terão oportunidade de iniciar a carreira na empresa atuando no cargo que condiz com sua formação.

A mudança deverá ocorrer em toda a organização, o prazo para implantação deverá ser estudado, pois os Recursos Humanos devem estar preparados para este novo tipo de recrutamento, além disso, o RH deverá montar uma equipe onde irá trabalhar somente neste projeto, a presidência e diretoria deverão acompanhar todo o processo, visto a grande complexidade.

Após a implantação deste plano de melhoria a organização deverá realizar o controle e a avaliação para verificar se o plano está sendo aplicado corretamente e para tomar algumas medidas de correções, se necessário.

\section{Considerações Finais}

Com base nos estudos e nas pesquisas realizadas na elaboração deste artigo concluise a viabilidade da implantação das propostas sugeridas no processo de Recrutamento e Seleção. Na organização em evidência, se identificam falhas no processo de Recrutamento e Seleção da organização que estão gerando impactos negativos em toda a organização. O plano de melhoria visa o sanar os principais problemas da área de Recursos Humanos e consequentemente melhorar toda a organização em si, e aumentar a motivação de profissionais do mercado em se candidatar a uma vaga da empresa.

Através dos fundamentos teóricos apresentados é pode-se observar que é possível proporcionar melhorias para a organização, abordando os pontos fracos analisados no Recrutamento e Seleção. Eles podem ser trabalhados para que não se tornem ameaça futura para o negócio da empresa. A partir dessa análise pode-se pensar uma estrutura mais adequada para que a empresa não seja afetada pelos fatores frágeis que foram detectados. Há possibilidade de se aproveitar as oportunidades para destacar a empresa no mercado pela visão satisfatória dos futuros funcionários. Assim esses já ingressam na organização com a motivação elevada.

Em virtude dos fatos expostos concluise que a empresa necessita de melhorias para que se tenha um impulso ainda maior na qualidade de seu serviço. Isso obtido permitirá a total satisfação entre os membros da organização elevando a imagem de sua marca no mercado. Melhorando a imagem da marca, melhora a satisfação do cliente interno e consequentemente do cliente externo que tiver as necessidades atendidas. Para que isso se mantenha precisa de pessoas bem preparadas. 


\section{Referências Bibliográficas}

1. ARAÚJO, L. C. GARCIA, A. A. Gestão de Pessoas, Estratégias e Integração Organizacional. $2^{a}$ Edição, São Paulo, 2009. ISBN 978-85-224-5602-4.

2. RIBEIRO, A. L. Gestão de Pessoas. $1^{\mathrm{a}}$ Edição, São Paulo, 2005. ISBN 978-85-0204985-7.

3. MAYO, A. O Valor Humano da Empresa. 1ª Edição, São Paulo, 2003.

4. ROBBINS, D. Administração de Recursos Humanos, $6^{a}$ Edição, Rio de Janeiro, 2001.

5. ROBBINS, P. S. Administração: Mudanças e Perspectivas, $8^{a}$ Edição, São Paulo, 2008.

6. SOBRAL, F.; PECI, A. Administração: Teoria e Prática no Contexto Brasileiro, Editora Pearson, São Paulo, 2012.

7. ARELLANO, E. B. Os processos de Recrutamento e Seleção. In: Fleury, M. T. L. (org.) As Pessoas na Organização. São Paulo: Gente, 2002.

8. FRANÇA, A. C. L. Recrutamento, Seleção e Testes Psicológicos: Práticas de Recursos Humanos: ferramentas e procedimentos. São Paulo: Atlas, 2007.

9. CHIAVENATO, I. Recursos Humanos. Rio de Janeiro: Elsevier, 2009.

10. PONTES, B. R. Planejamento, Recrutamento e Seleção de Pessoal. 2 ${ }^{\mathrm{a}}$ Edição. São Paulo: LTR, 1996.

11. FIORELLI, O. J. Psicologia para Administradores. São Paulo: Atlas, 2007.
12. WELCH, J. Capital Intelectual. In: MAYO, A. Administração de Recursos Humanos, $6^{a}$ Edição, Rio de Janeiro, 2001.

13. THE TIMES. Pessoas como principal ativo da organização. In: MAYO, A. Administração de Recursos Humanos, $6^{a}$ Edição, Rio de Janeiro, 2001.

14. CHIAvenAtO, I. "Gestão de Pessoas; o novo papel dos recursos humanos nas organizações" - ED Elsevier, 1999 - Rio de Janeiro.

15. SORIO, Washington. - 2007 capturado em www.rhportal.com.br/artigos em 22/10/2009.

16. LODI, J.B. "Recrutamento de Pessoal". São Paulo, Pioneira, 1967.

17. NUNES, Gilvan as Silva "Recrutamento e Seleção". São Paulo, Érica, 2002.

18. GOMES, M. A. N.; FILHO, E. E. Análise dos processos de recrutamento e seleção na pequena empresa: estudo multicasos no setor metal-mecânico de São Carlos - SP. In: EGEPE, 2. 2001, Londrina PR. Anais eletrônicos. Londrina: 2001. Disponível em: http://www.dad.uem.br/ egepe2/GPE2001-15.pdf. Acesso em: 13 set. 2012.

19. ARRUDA, J. Consultora da Associação Brasileira de Recursos Humanos. Recrutamento e Seleção. Disponível em: www.abrhrj.org.br/typo/index. php?id=385. Acesso em 13 set. 2012.

20. SILVA, L. M. C. Faculdade de ciências aplicadas e sociais de Petrolina. Capital intelectual. Trabalho acadêmico pág. 01. Disponível em: www.facape.br/socrates /trabalhos/capital\%20intelectual.htm.

Acesso em: 13 set. 2012.. 